\title{
Scaffolds in Regenerative Endodontics: A Review
}

\author{
Malli Sureshbabu Nivedhitha ${ }^{1}$, Selvam Deepak ${ }^{2}$, Benoy Jacob ${ }^{3}$, Riluwan Siddique ${ }^{4}$
}

\begin{abstract}
Stem cells, scaffolds, and growth factors, each of which possesses unique biological capabilities, constitute what is known as the tissue engineering triad. Recently, regenerative endodontics has emerged as a new field that deals with the rejuvenation of the pulp-dentin complex in necrotic immature permanent teeth, regeneration of bone, periodontal ligament and cementum in cases with large periapical lesion, and regeneration of periodontal tissue and bone in endo-perio lesions. Scaffolds play a major part in the formation of the extracellular matrix by providing support to cells to adhere, grow, and differentiate. In this review, four major categories of scaffolds (autologous platelet concentrates, nanofibrous scaffolds, injectable scaffolds, and bioactive molecule carrier systems) used in regenerative endodontics have been discussed in detail.
\end{abstract}

Keywords: Autologous platelet concentrates, Bioactive molecules carrier system, Electrospun nanofibers, Injectable scaffolds, Pulp-dentin regeneration, Regenerative endodontics, Scaffolds.

Journal of Operative Dentistry and Endodontics (2020): 10.5005/jp-journals-10047-0098

\section{INTRODUCTION}

Stem cells, scaffolds, and growth factors, each of which possesses unique biological capabilities, constitute what is known as the tissue engineering triad. The differentiation potential of stem cells (undifferentiated cells) to differentiate to a particular tissue in a suitable medium (scaffold) under the influence of growth factors or bioactive molecules, holds significant credibility in regenerative therapeutic procedures.

Recently, regenerative endodontics has emerged as a new field that deals with the rejuvenation of the pulp-dentin complex in necrotic immature permanent teeth, regeneration of bone, periodontal ligament and cementum in cases with large periapical lesion, and regeneration of periodontal tissue and bone in endo-perio lesions.

The scaffold can be defined as a three-dimensional microstructural network of biologically active compounds, all working in tandem to ensure the safe delivery of bioactive cells, which are highly essential for facilitating tissue repair and regeneration.

Primarily, scaffolds play a major part in the formation of the extracellular matrix (ECM) by providing support to cells to adhere, grow, and differentiate.

The functions (Fig.1), ideal requirements (Fig. 2) $)^{1,2}$, and classification of scaffolds (Fig. 3$)^{3}$ are illustrated in the mind maps.

In this review, four major categories of scaffolds (autologous platelet concentrates [APC], nanofibrous scaffolds, injectable scaffolds, and bioactive molecule carrier systems) used in regenerative endodontics will be discussed in detail.

\section{Autologous Platelet Concentrates Platelet-rich Plasma}

Platelet-rich plasma (PRP), an autologous first-generation platelet concentrate, has to its credit an abundant reservoir of growth factor content, thereby ideally labelling it as a scaffold. ${ }^{4}$

\section{Platelet-rich Fibrin (PRF)}

The second-generation platelet concentrate is composed of an intertwined fibrin mesh of cytokines, glycanic chains, and structural

\begin{abstract}
1,2 Department of Conservative Dentistry and Endodontics, Saveetha Dental College and Hospital, Saveetha Institute of Medical and Technical Sciences, Saveetha University, Chennai, Tamil Nadu, India

${ }^{3}$ Private Practice, Consultant Endodontist, Muthusaram Healthcare Pvt. Ltd., Chennai, Tamil Nadu, India

${ }^{4}$ Private Practitioner, Consultant Endodontist, Karikulam Dental Clinic, Malikampeedika, Aluva, Kerala, India

Corresponding Author: Malli Sureshbabu Nivedhitha, Department of Conservative Dentistry and Endodontics, Saveetha Dental College and Hospital, Saveetha Institute of Medical and Technical Sciences, Saveetha University, Chennai, Tamil Nadu, India, e-mail: nivedhithamallisureshbabu@gmail.com

How to cite this article: Nivedhitha MS, Deepak S, Jacob B, et al. Scaffolds in Regenerative Endodontics: A Review. J Oper Dent Endod 2020;5(2):88-98.

Source of support: Nil

Conflict of interest: None
\end{abstract}

glycoproteins. The concoction provides an astounding effect on wound healing and repair. ${ }^{5}$

Dohan enlisted a set of platelet concentrates into four families, according to their leukocyte content and fibrin architecture: pure platelet-rich plasma (P-PRP), leukocyte- and platelet-rich plasma (L-PRP), pure platelet-rich fibrin (P-PRF), and leukocyte- and platelet-rich fibrin (L-PRF).

Platelet concentrates have been widely used in regenerative endodontics as a scaffold material. Platelets are considered the powerhouse of growth factors, released during wound healing for repair and regeneration. In the endodontic literature, a wide array of cases concerning the application of APCs for the management of necrotic immature permanent teeth have been reported, highlighting promising outcomes for the same. There are nine clinical trials ${ }^{6-14}$ and four systematic reviews ${ }^{15-18}$ on this topic. According to the Oxford CEBM, both have a higher level of evidence.

The different outcomes that were evaluated for the regenerative endodontic procedures were healing or reduction 

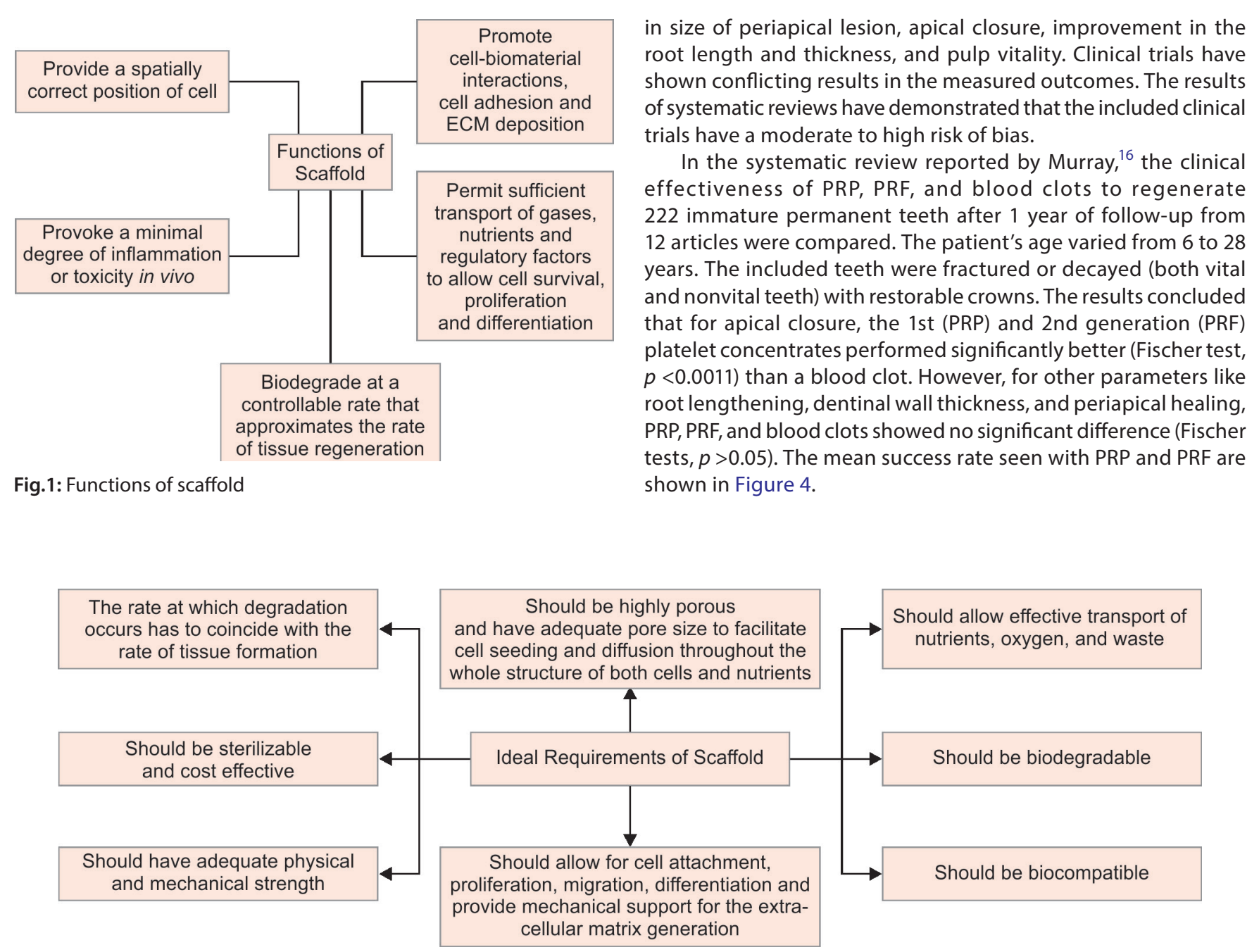

Fig. 2: Ideal requirements of scaffold

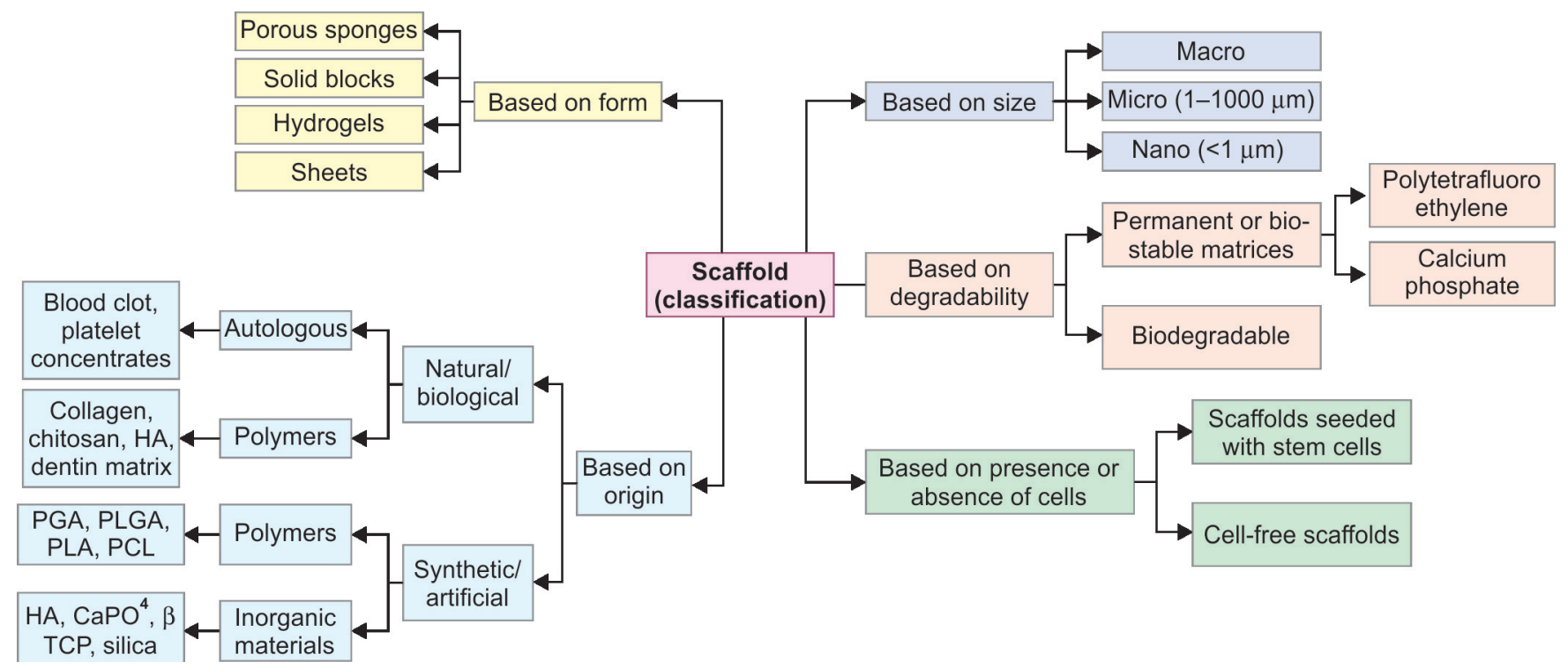

Fig. 3: Classification of scaffold 
In another systematic review done by Metlerska et al., ${ }^{17}$ among the 26 studies included in the systematic review, five were randomized trials. In randomized trials, only three cases were unsuccessful, and those salvaged with APCs exhibited a higher response to pulp vitality tests. In most included subjects, thickening of dentinal wall layers, increase in the length of the root, and even closure of the apical portion of the root were noted.

The concluding remark derived from the meta-analysis was that there was a marked improvement in apical closure and subsequent responses to pulp vitality tests revealed an overall successful treatment outcome. ${ }^{17}$ On the other hand, there was no significant increase in root length or dentinal wall thickness. In the subgroup analysis, there was a better effect in apical closure in teeth treated with PRP when compared to PRF, also the pulp vitality tests were adequate for PRP (Fig. 5).
With mounting evidence, a conclusion can be drawn in favor of regenerative endodontics, to serve as a prudent therapeutic option in dealing with immature necrotic teeth, with an overall success rate of $96.5 \%$ recorded for the same. However, a longer follow-up period of 5 years or more is essential to gain complete acceptance of the treatment regimen, which is again currently absent in the literature.

\section{Plasma Rich in Growth Factors}

Plasma rich in growth factors (PRGF) technology developed by Anitua, is a first-generation platelet concentrate consisting of a plasma infused autologous platelet concentrate devoid of leucocytes. PRGF is an autologous platelet concentrate with growth factors in abundance, such as platelet-derived growth factor (PDGF), vascular endothelial growth factor (VEGF), transforming

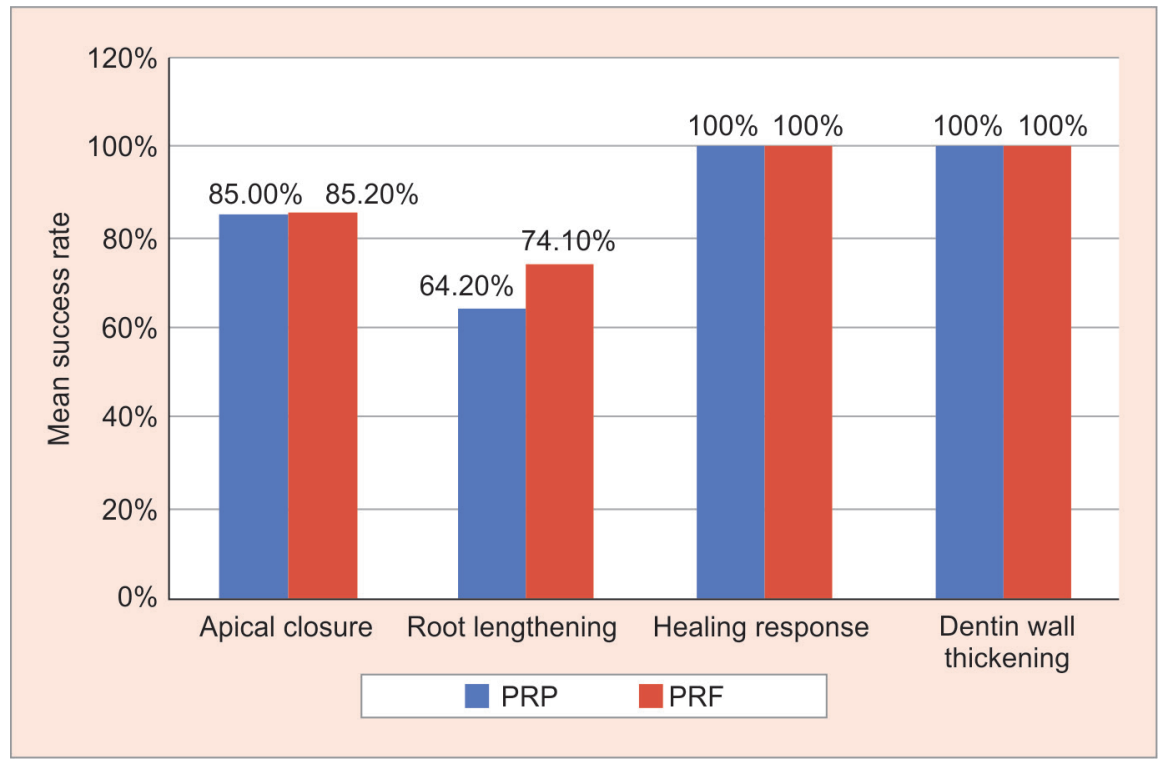

Fig. 4: Bar chart for the mean success rate of PRP vs PRF

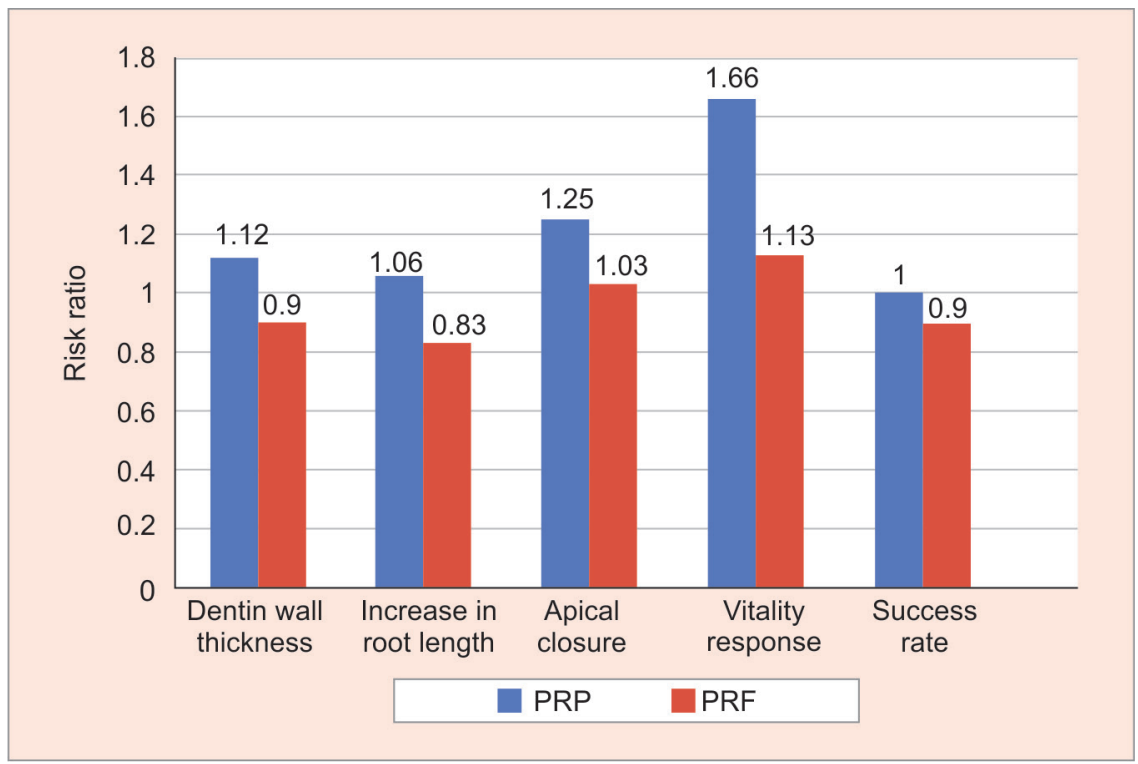

Fig. 5: Bar chart comparing the effectiveness of PRP vs PRF in terms of risk ratio 
growth factor-beta (TGF- $\beta$ ), fibroblast growth factor (FGF), epidermal growth factor (EGF), insulin-like growth factor (IGF-1), and hepatocyte growth factor (HGF). ${ }^{19}$

\section{PRGF Preparation}

A sterile environment is maintained throughout the blood collection procedure, wherein blood is drawn in $3.8 \%$ sodium citrate tubes, following which tubes are centrifuged at $460 \times \mathrm{g}$ for 8 min (PRGF System, BTI Biotechnology Institute, Álava, Spain). Blood dissociates into three fractions: the topmost layer of plasma containing platelets, the middle layer enriched with white blood cells also forming a "buffy coat" and finally, the bottom layer comprising of red blood cells. The portion above the first layer, i.e., plasma poor in growth factors (PPGF), and the portion right above the "buffy coat" (PRGF) are dispensed into separate tubes, keeping in mind no additives are to be added. Calcium chloride, the compound used to activate the PRGF concentrate is added to the preparation $(50 \mu \mathrm{L} \mathrm{CaCl} / \mathrm{mL}$ of preparation), subsequently achieving platelet degranulation and the release of growth factors as an outcome.

In a case series reported by Hengameh Bakhtiar et al., PRGF has demonstrated encouraging outcomes in the management of necrotic immature teeth. After two years of follow-up, 2 teeth showed complete apical closure and in another 2 teeth, apical closure and thickening of the dentinal wall were observed. ${ }^{20}$ PRGF has also been applied for large through-and-through bone lesions and perforation of sinus membrane with or without bone grafts. Patients' quality of life was improved during the initial postoperative healing period after the use of PRGF. PRGF has also shown accelerated bone healing in periradicular sur23gery. ${ }^{21-23}$

\section{Concentrated Growth Factor}

The stem cells of the apical papilla (SCAP) tend to exert a "self-renewing" property, which is believed to be the biological mechanism promoting adequate regeneration to acceptable levels highlighting the capability of differentiation into odontoblast-like cells, ultimately producing tissue, very much similar to the dentin microstructure. ${ }^{24,25}$ The preservation of SCAP proves to be a forerunner in regenerative endodontics promoting the adequate formation of the root from development to its completion. ${ }^{26} \mathrm{~A}$ direct infusion of substantial amount of mesenchymal stem cells (MSCs) into the root canal space on induction of bleeding from the apical papilla cannot be expected and whatever quantity begot will be insufficient to reinvigorate the pulp-dentin complex. ${ }^{27}$ Thus, concentrated growth factor (CGF) succors to stem the regenerative process by serving as a prudent cenote of growth factor content. ${ }^{28}$ Comparison of all the four platelet concentrates is given in Table 1.

CGF, introduced by Sacco et al., is a second-generation APC capable of bringing about a revolutionary change in regenerative endodontic procedures. To put it in perspective, CGF in comparison with older platelet concentrates exhibits differing characteristics by the manner in which it is concocted. The distinctive centrifugation technique that is subjected to much more improved, distinct, and healthier fibrin matrix, accredited to diverse time intervals and controlled speeds, channeled during the centrifugation process. ${ }^{29}$ In a comparative study, it was demonstrated that CGF undoubtedly held an edge over PRP and PRF in terms of not only cell proliferation and osteoblastic differentiation but also possessed a richer growth factor content. ${ }^{30}$

\section{Preparation of CGF}

A centrifuge machine (MEDIFUGE, Silfradentsrl, S. Sofia, Italy) and a couple of disposable $10 \mathrm{~mL}$ non-anticoagulant centrifuge tubes are the equipments to be kept ready at first. Thereafter, after seating the patient, $10 \mathrm{~mL}$ of intravenous blood is drawn from the patient, chairside, and transferred to centrifuge tubes. It should be kept in mind that no anticoagulants are used during the preparation process. The tubes are then churned inside, accelerated for $30 \mathrm{~s}$, centrifuged at $2700 \mathrm{rpm}$ for $2 \mathrm{~min}, 2400 \mathrm{rpm}$ for $4 \mathrm{~min}, 2700 \mathrm{rpm}$ for $4 \mathrm{~min}$, and $3000 \mathrm{rpm}$ for $3 \mathrm{~min}$, decelerated

Table 1: Autologous platelet concentrates

\begin{tabular}{|c|c|c|c|c|}
\hline & $P R P$ & PRGF & PRF & CGF \\
\hline Pioneers & Whitman et al. ${ }^{4}$ & Anitua $^{19}$ & Choukroun et al. ${ }^{5}$ & Sacco et al. ${ }^{29}$ \\
\hline Generation & 1st generation & 1st generation & 2nd generation & 2nd generation \\
\hline Growth factors & PDGF, VEGF, TGF-ß & PDGF, TGF-ß, IGF & $\begin{array}{l}\text { PDGF, TGF- } \beta \text {, cytokines } \\
\text { (sustained release) }\end{array}$ & $\begin{array}{l}\text { BMPs, osteo-conductive fibrin } \\
\text { matrix }\end{array}$ \\
\hline Anticoagulants & Used & Used & Not used & Not used \\
\hline Bovine thrombin & Used & Not used & Not used & Not used \\
\hline Preparation & $\begin{array}{l}\text { Blood centrifuged in } 2 \text { spins: } \\
\text { Soft spin: } 1300 \mathrm{rpm}-10 \mathrm{~min} \\
\text { Hard spin: } 2000 \mathrm{rpm}-10 \mathrm{~min}\end{array}$ & $\begin{array}{l}\text { Blood centrifuged at } \\
460 \times g \text { for } 8 \text { min } \\
\mathrm{CaCl}_{2} \text { is added as PRGF } \\
\text { activator }\end{array}$ & $\begin{array}{l}\text { Blood centrifuged at } 3000 \\
\mathrm{rpm} / 400 \times \mathrm{g} \text { for } 10 \mathrm{~min}\end{array}$ & $\begin{array}{l}\text { Blood centrifuged at different } \\
\text { speeds: } 2700 \mathrm{rpm} \text { for } 2 \mathrm{~min} \text {, } \\
2400 \mathrm{rpm} \text { for } 4 \mathrm{~min}, 2700 \mathrm{rpm} \text { for } \\
4 \mathrm{~min} \text {, and } 3000 \mathrm{rpm} \text { for } 3 \mathrm{~min} \text {, } \\
\text { decelerated for } 36 \mathrm{~s} \text { to stop }\end{array}$ \\
\hline Advantages & $\begin{array}{l}\text { Easy to prepare, rich in GF, } \\
\text { form 3D fibrin that entraps GF }\end{array}$ & $\begin{array}{l}\text { Shortest centrifuge } \\
\text { cycle, easy preparation }\end{array}$ & $\begin{array}{l}\text { Easy to prepare, shorter cen- } \\
\text { trifuge cycles, no coagulant } \\
\text { required, long-acting, more } \\
\text { effective }\end{array}$ & $\begin{array}{l}\text { Does not require additives, bet- } \\
\text { ter results compared to PRP, PRF }\end{array}$ \\
\hline Disadvantages & $\begin{array}{l}\text { Lesser cytokines, short-acting, } \\
\text { bovine thrombin-life-threat- } \\
\text { ening coagulopathies, long } \\
\text { preparation time }\end{array}$ & $\begin{array}{l}\text { Less active than PRF, } \\
\text { CGF. Low levels of } \\
\text { growth factor release }\end{array}$ & $\begin{array}{l}\text { Used in limited volumes, } \\
\text { tissue banks for PRF are un- } \\
\text { feasible, shrinks on storage }\end{array}$ & $\begin{array}{l}\text { Requires special centrifuge } \\
\text { machine }\end{array}$ \\
\hline
\end{tabular}

BMP, bone morphogenetic protein; CGF, concentrated growth factor; PDGF, platelet-derived growth factor; PRF, platelet-rich fibrin; PRF, platelet-rich fibrin; PRP, platelet-rich plasma; VEGF, vascular endothelial growth factor 
for $36 \mathrm{~s}$ to stop. At the end of the automated pre-programmed cycle, the centrifuge tube encompass a mixture of four separate portions one above the other: the last layer (4th) comprises the red blood cells (RBCs), the one above it (3rd) constitutes the growth factor content, the secondary layer (2nd) is composed of a "buffy coat", and the primary portion (1st) contains serum. The 3rd portion, i.e., the fibrin gel containing the much need concentrated growth factor content (CGF) is separated from the 4th portion of RBCs.

In yesteryears, primary emphasis has been laid upon the incorporation of the most sought-after APCs namely PRP and PRF in a process to regenerate the lost pulp. The main listed disadvantages of the older generation platelet concentrate include high cost, difficulty in centrifugation, handling, and purification procedures. CGF scores over all the aforementioned drawbacks especially in terms of low cost and easy handling, the use of anticoagulants and bovine thrombin are also avoided..$^{31}$ Additional benefit of CGF, when compared to conventional platelet concentrates is that CGF acts as a promising biomaterial releasing growth factors that induce cell migration and proliferation, chemotactic activity on inflammatory cells, stimulates angiogenesis and tissue remodeling. ${ }^{32}$ CGF plays an important role in implant surgeries and sinus ridge augmentation procedures. $^{33}$

CGF in combination with osseograft has several advantages in the formation of sticky bone. The formed product can be molded, prevent both macro and micro-movements, also the mesh network contains growth factors and platelets thereby contributing to accelerated bone regeneration and soft tissue healing. The fibrin interconnection network also helps to prevent the ingrowth of soft tissue into the bone graft. ${ }^{34}$

CGF accounts for a diverse array of growth factors, such as platelet-derived growth factor (PDGF), transforming growth factor (TGF-ß1 and TGF-ß2), fibroblast growth factor (FGF), vascular endothelial growth factor (VEGF), and insulin-like growth factor (IGF), of which TGF-ß1 and VEGF predominate. Rodella et al., demonstrated that growth factors TGF-ß1 and VEGF were found in abundance which according to the literature are highly essential for stimulating cell proliferation, matrix rehabilitation, and angiogenesis. The aforesaid study also confirmed the existence of circulating CD34+ cells in CGF and RBC layers which again is an important requisite for the revascularization process. ${ }^{35}$ While TGF- 11 stimulates expression of bone morphogenetic proteins (BMPs), curtails matrix metalloproteinases (MMPs) and other enzymes to further promote differentiation of osteoblastic cells, ${ }^{36}$ VEGF at the same time induces endothelial cell migration and proliferation eventually leading to hyperpermeability of blood vessels. ${ }^{37}$ In a study done by Park et al., showed a higher level of growth factors, particularly VEGF in CGF as opposed to PRF. ${ }^{38}$

The results of initial in-vitro studies on the usage of CGF in regenerative endodontics are successful. The biological effects of CGF on both SCAP and dental pulp stem cells (DPSC) have been studied extensively. Hong et al. ${ }^{39}$ evaluated the effects of CGF on SCAP and reported that CGF promoted the proliferation, migration, and differentiation of SCAPs and recommended it as a successful biomaterial for usage in regenerative endodontics. In another comparative study by Hong et al., ${ }^{40}$ CGF and PRF were compared on the effects of SCAP. The results of the study concluded that both test groups demonstrated significantly greater mineralized areas than the control groups. The expression levels of alkaline phosphatase (ALP), bone sialoprotein (BSP), dentin matrix protein 1 (DMP-1), and dentin sialophosphoprotein (DSPP) were down-regulated after incubation in CGF and PRF for 7 days, whereas they were significantly enhanced after incubation for 14 days. Also, the expression levels of related genes in the PRF group were statistically higher than those in the CGF group.

Jin et al., ${ }^{41}$ assessed the effects of various concentrations of CGF on DPSC and reported an interesting finding. The low doses $(<50 \%)$ of CGF increased cell migration, ALP activity, and mineralized tissue deposition, while the cells treated in high doses $(50 \%$ or $80 \%)$ showed no significant difference. Jun et al., ${ }^{42}$ demonstrated that extracts of CGF upregulated the expression of angiogenesis-related genes in human dental pulp cells and human umbilical vein endothelial cells.

In our previously published case report presentation of two cases, we had used CGF as a scaffold in the endo surgical treatment procedures and had showed promising healing outcomes. ${ }^{43}$ Also, use of CGF has shown good result in the treatment of NIPT. ${ }^{44}$ In another case report, we had implemented a coalescence of CGF and bone graft (sticky bone) to intercept a large periapical bony lesion and had showcased exceptional results in terms of periapical healing which is probably ascribable to the inclusion of a dynamic combination of CGF and bone grafts to form sticky bone as a means to induce a rapid repair and regenerative process. ${ }^{45}$ In the latest clinical trial, the combination of bone graft along with CGF had been proven to be significantly better than the use of bone graft alone in treating jawbone defects due to various etiologies. ${ }^{46}$

\section{Nanofibrous Scaffold}

Ideally, a scaffold should accurately reproduce the features of the native ECM at the nanoscale to regulate cellular responses, encourage and regulate specific events at the cellular and tissue levels. ${ }^{47}$ Nanofibrous polymer scaffolds are tailored to show high processing ability, mechanical competence, characteristically biodegradable and biocompatible as well. Certain features, such as interconnected porosity, high surface area and nano fiber dimension propel nano fibrous scaffolds as such much more superior competitor to microfibers or any other morphological arrangements. Most significantly, nanofibrous scaffolds are best-known to stimulate positive cell-ECM interactions, maintain cell phenotype, support differentiation of stem cells, increase cell proliferation, and activate cell signaling pathways by imparting physical and chemical stimuli. The advantages, techniques of fabrication, classification, and recent advances are given in the mind map (Fig. 6).

Electrospinning or electrostatic spinning-by adjustment of electrospinning parameters, fiber morphology is controlled, along with fiber diameter, fiber, and pore size, among different factors identified to influence cell behavior and overall tissue regeneration. ${ }^{48}$ Nanofibrous scaffolds have two different applications in regenerative endodontics. The first application is for intracanal drug delivery of antibiotics. The second application is for promoting dentin-pulp regeneration.

Intracanal drug delivery of antibiotics using electrospun nanofibers has been extensively studied in in-vitro studies. ${ }^{49}$ The antibiotics that are commonly used are ciprofloxacin, metronidazole, and minocycline. They have been tested individually or in different combinations for antimicrobial 


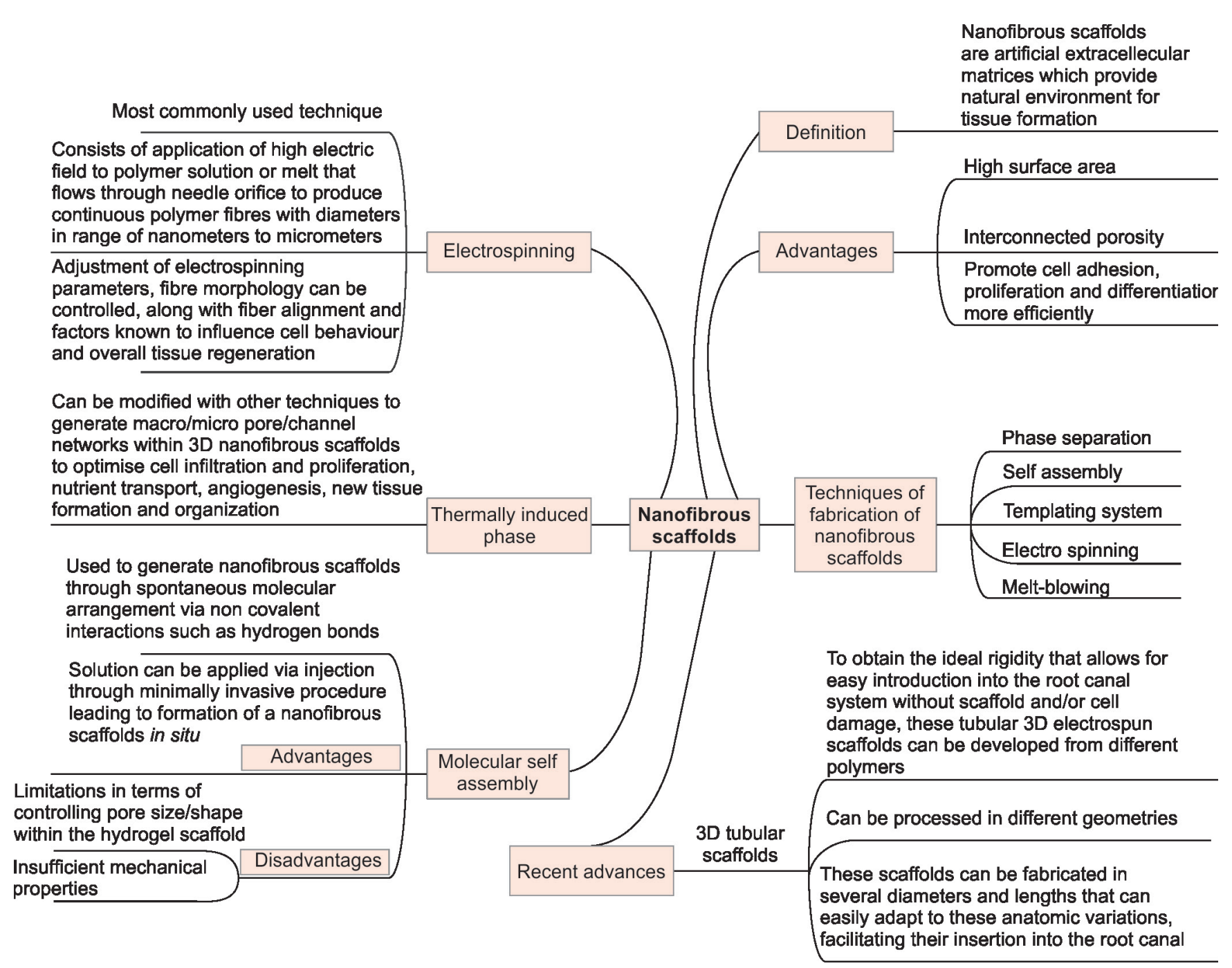

Fig. 6: Nanofibrous scaffolds

properties and cytotoxicity against stem cells. These antibiotics have proved to be effective against Enterococcus faecalis, Porphyromonas gingivalis, and Fusobacterium nucleatum. ${ }^{50-52}$ Replacing minocycline with clindamycin (Clindamycin modified TAP) in the nanofibers showed no visible dentin discoloration. This modified antibiotic paste can be considered as an alternative to the minocycline containing triple antibiotic paste (TAP) which causes staining of tooth structure. ${ }^{53}$

A study done by Ruparel et al. has shown that the widely used creamy paste $(1 \mathrm{~g} / \mathrm{mL})$ of the triple antibiotic mixture is harmful to stem cells from the apical papilla (SCAPs). However, TAP concentrations starting from 0.01 to $0.1 \mathrm{mg} / \mathrm{mL}$ were not cytotoxic, and also the concentration of $1 \mathrm{mg} / \mathrm{mL}$ was solely moderately harmful once applied directly onto SCAP and had no result on viability. ${ }^{54}$ Nanofiber-based scaffold designed for intracanal drug delivery release antibiotics at lower concentrations, nevertheless antimicrobially effective. Because of the lower concentration of antibiotics released, they are less cytotoxic to the stem cells. ${ }^{55}$ Antibiotic-containing scaffolds minimize harmful effects of highly concentrated antibiotic pastes on stem cell of apical papilla survival and nonetheless still promote bacterial elimination based on high-performance liquid chromatography (HPLC) analysis data, in addition to cell toxicity experiments, has supported the claim of an additional biologically friendly strategy compared with the use of antibiotic pastes, since the amount of drugs released occurs more gradually in a lower concentration than in those used in pastes. ${ }^{49}$

Various studies have shown encouraging results for odontogenic differentiation of human DPSC on different nanofibrous scaffolds (poly(lactic acid) (PLA), polycaprolactone $(\mathrm{PCL})$, nano-hydroxyapatite ( $\mathrm{nHA}$ ) incorporated, collagen, gelatin). Future studies will be conducted for carrying dental derived em cells in electrospun nanofibers for optimum dentin-pulp regeneration. ${ }^{47}$

\section{InJectable Scaffold}

The root canal system has a complicated morphological structure with a long, narrow channel of the root canal with an average total volume of $20 \mu \mathrm{L}$. It is always a challenge to place the preformed scaffolds (sheets, blocks) into the root canal space. In this regard, an injectable scaffold has several advantages. These include (a) it can be easily implanted into the root canal space by injecting it as it is available in the liquid form, (b) it can easily fill any irregularly shaped 
defects, (c) stem cells and bioactive molecules can be easily mixed with the solution before injecting in situ, and (d) the placement of scaffold is done in a minimally invasive manner which reduces the risk of infection and improves the comfort. ${ }^{56}$

The requirements, classification, fabrication methods, materials used for injectable scaffolds are shown in the mind map (Fig. 7). ${ }^{57}$ Injectable hydrogels are composed of three-dimensional hydrophilic polymers that absorb water or tissue fluids up to several times their weight (Fig. 8). ${ }^{58}$ These are biocompatible, tunable, water-swollen materials that can be easily injected in their colloidal form, undergoing gelation by chemical (e.g., changes in $\mathrm{pH}$ and osmolarity) or physical stimuli (e.g., temperature change). It can be easily injected into narrow root canal spaces and can be modified to deliver chemotactic and angiogenic agents to drive stem cell homing and supportive angiogenesis. ${ }^{58}$ The properties of hydrogels are given in the mind map (Fig. 9).

Hydrogels made of self-assembly peptides (e.g., PuraMatrix ${ }^{\mathrm{TM}}$ ) show great potential to be used in endodontic tissue engineering because their sequence includes short peptide sequences, like those naturally occurring in tissues, enhancing cell attachment and proliferation. PuraMatrix ${ }^{\mathrm{TM}}$ is a successful hydrogel-based nanofibrous scaffold made of 16-mer peptide in an aqueous solution. On interaction with physiological conditions, it polymerizes and forms a biodegradable nanofiber hydrogel scaffold. The selfassembling design presents limitations relative to mechanical properties and structure-examples, the influence of viscosity in cell proliferation, irregular pore size, and difficulty maintaining the hydrogel throughout the full-length of root canal extension. ${ }^{56}$

Many injectable hydrogels have been evaluated against DPSC, SHED, and SCAP for their survival and differentiation. PuraMatrix promoted the survival and proliferation of DPSC. ${ }^{59}$ SHED encapsulated in PuraMatrix and delivered into whole root canals gave rise to a pulp-like tissue and odontoblasts after transplantation into immunodeficient mice. ${ }^{60}$ In another study, the scaffold was used with DPSC and human umbilical vein endothelial cells (HUVEC) and demonstrated that DPSCs showed higher early vascular network formation by facilitating the migration of HUVECs and by increasing vascular endothelial growth factor (VEGF) expression. ${ }^{61}$ Application of scaffold mixed with SCAP without the use of exogenous growth factors and transplanted into molar crowns of mice, formed a viable tissue with odontoblast-like cells. ${ }^{62}$

A hydrogel composed of PEGDA, HN, and Gn (HyStem C) was assessed against DPSC and it was shown that it maintains viability and facilitates cell spreading in the presence of extracellular matrix proteins. ${ }^{63}$ Another FDA authorized hyaluronic acid-based hydrogel (Restylane) which has been widely used as facial dermal filler promoted stem cells of apical papilla survival, mineralization, and differentiation into an odontoblastic phenotype. ${ }^{64}$ Shiehzadeh et al. reported in their case report about the use of injectable scaffold to deliver dental stem cells for the management of large periapical lesions. ${ }^{65}$

Recently, Fukushima et al. have done a systematic review after screening articles based on various hydrogel-based scaffolds used

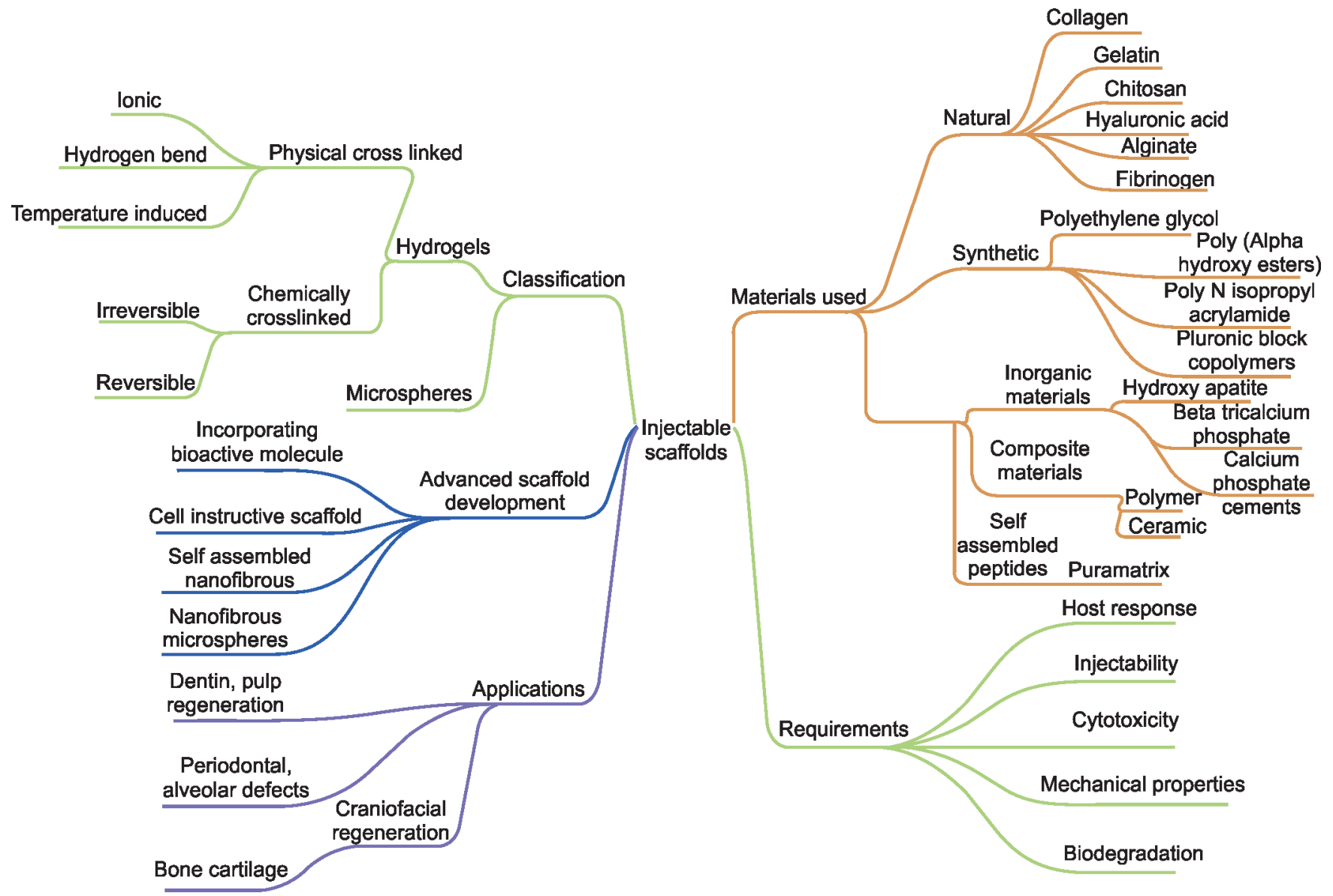

Fig. 7: Injectable scaffolds 


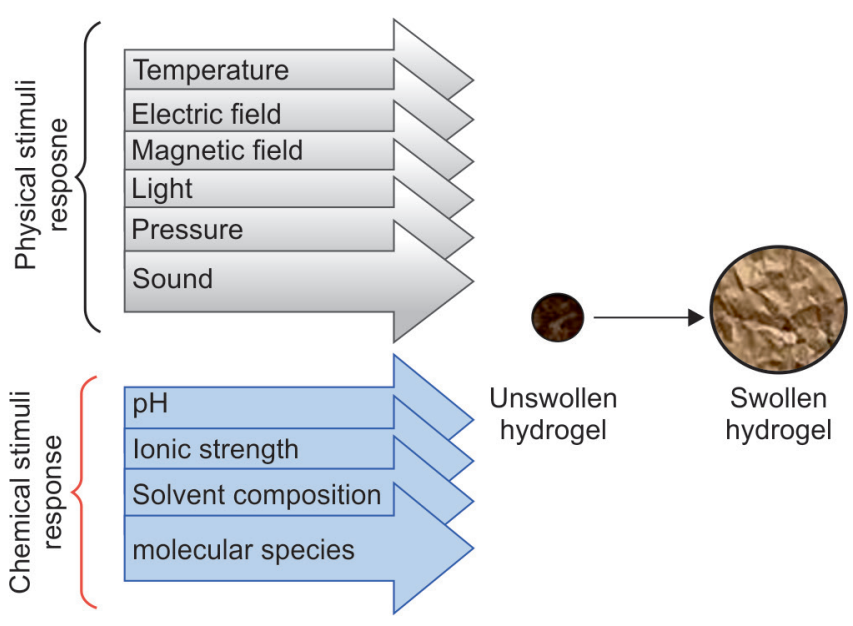

Fig. 8: Hydrogels: Response to stimuli

for regeneration of dental pulp. ${ }^{66}$ Their conclusion has shown that the appropriate hydrogel scaffold type to be used along with stem cells for regeneration of dental pulp was the natural scaffold. Collagen was the most successful natural scaffold. Even without the use of growth factors, the scaffolds having stem cells were able to support the dentin formation whereas synthetic scaffolds were least preferred. PuraMatrix by itself was unable to form dental pulp when DPSC were not present. Synthetic and hybrid hydrogels were unable to attract stem cells from the host. The presence of growth factors in these constructs seems to be of relevance since dental pulp tissue formation was achieved only when the hybrid scaffold was applied with growth factors. All types of hydrogel-based scaffolds, when containing mesenchymal stem cells, can form connective tissue with different degrees of similarity to the dental pulp. ${ }^{6}$

\section{Bioactive Molecule Delivery System}

Bioactive molecules are signaling molecules, such as growth factors or chemical cues that control a variety of cellular responses through specific binding of transmembrane or intracellular receptors in a target cell. ${ }^{67}$

Dentin and pulp are two ultrastructurally different tissues. However, they are considered as a single unit (dentin-pulp complex). During physiologic tooth development, bioactive molecules are released in a controlled manner to the desired location (spatiotemporal release-both location and time-specific). In the regenerative endodontic procedure, there is a great challenge for the accurate release of bioactive molecules in a spatiotemporal manner. ${ }^{68}$

Bioactive molecule carrier system (BACS) aids in mimicking some of the complex physiological processes, overcoming some of the challenges faced in the clinical translation of regenerative endodontic procedures. Also, the biomaterial-based BACS, with the aid of encapsulated bioactive molecules plays an important role in activating critical cellular signals, microenvironmental cues capable of modulating and tailoring cellular responses. The ideal requirements, release mechanisms, and release kinetics of BACS are given in the mind map (Fig. 10).

When the bioactive molecules are administered in a bulk or bolus form the release pattern follows the first-order kinetics. This strategy has the increased concentration initially followed by a drastic decrease in concentration. To overcome this challenge, different strategies have been employed to maintain the release of bioactive molecules. Various carrier materials have been developed to tailor the release of bioactive molecules. In the sustained release strategy, the molecules are released above the therapeutic level for a longer period of time. The more sophisticated controlled-release strategy releases the molecules at a specific rate for a much longer time which follows the zero-order principle.

The most commonly used carrier material is collagen which is a natural polymer. Other natural polymer materials include hyaluronic acid, alginate, and chitosan. These are employed in different forms, such as three-dimensional scaffolds, hydrogels, and micro/ nanoparticles for the controlled release. In recent years, chitosan has been used in a nanoparticulate form as a delivery system for bioactive molecules.The molecules tried are the bovine serum albumin (BSA), dexamethasone (DEX), TGF- $\beta 1$ and have been tested against the SCAP. The temporally controlled release of BSA and DEX from chitosan nanoparticle carrier systems have promoted the proliferation, ALP activity, and odontogenic differentiation of SCAP. ${ }^{69,70}$ The sustained release of TGF- $\beta 1$ enhanced the migration and differentiation of SCAP cells. ${ }^{71}$

\section{Conclusion}

This literature review focuses on the advantages and limitations of various scaffolds used in regenerative endodontics. Autologous

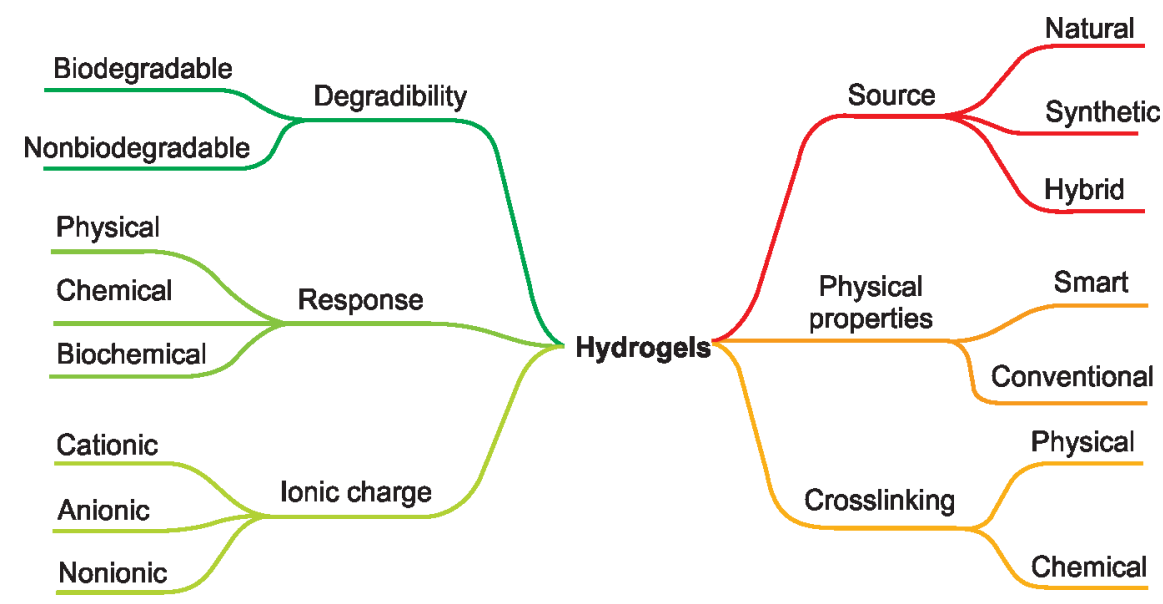

Fig. 9: Hydrogels 


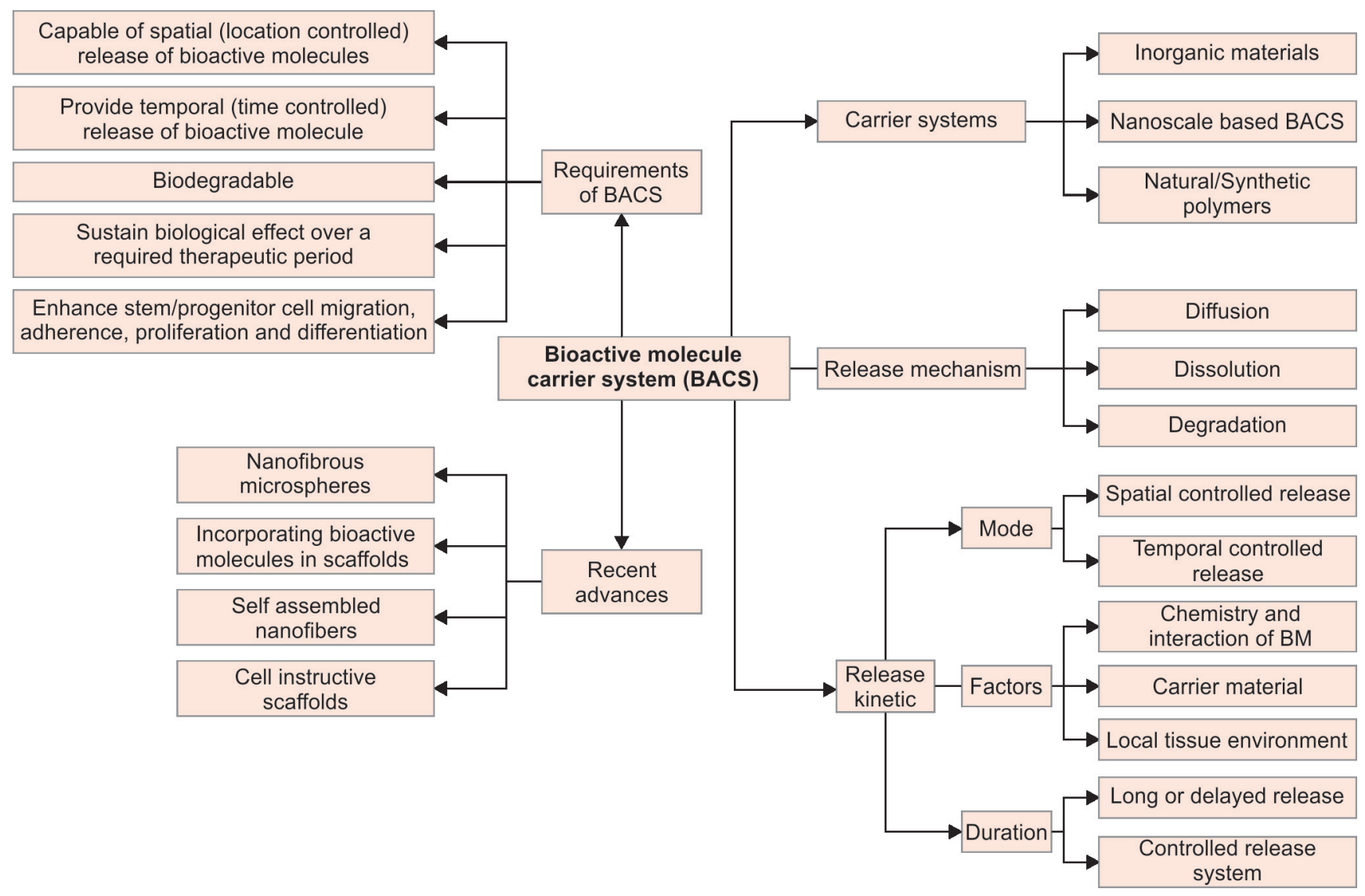

Fig.10: Bioactive molecule carrier system

platelet concentrates are the commonly employed scaffold because of their ease of use and biocompatibility. To overcome its drawbacks, other scaffolds are developed. However, many of them are still in laboratory research with promising results. More animal and clinical studies should be done to translate the application of newer scaffolds in regenerative endodontics.

\section{References}

1. Gathani KM, Raghavendra SS. Scaffolds in regenerative endodontics: a review. Dent Res J 2016;13(5):379-386.

2. Alshehadat SA, Thu HA, Hamid SS, et al. Scaffolds for dental pulp tissue regeneration: a review. Int Dent Med J Adv Res 2016;2(1):1-12. DOI: 10.15713/ins.idmjar.36.

3. Shrestha S, Kishen A. Bioactive molecule delivery systems for dentinpulp tissue engineering. J Endod 2017;43(5):733-744. DOI: 10.1016/j. joen.2016.12.020.

4. Whitman DH, Berry RL, Green DM. Platelet gel: an autologous alternative to fibrin glue with applications in oral and maxillofacial surgery. J Oral Maxillofac Surg 1997;55(11):1294-1299. DOI: 10.1016/ s0278-2391(97)90187-7.

5. Choukroun J, Adda F, Schoeffer C, et al. PRF: an opportunity in perioimplantology. Implantodontie 2001;42:55-62.

6. Jadhav G, Shah N, Logani A. Revascularization with and without platelet-rich plasma in nonvital, immature, anterior teeth: a pilot clinical study. J Endod 2012;38(12):1581-1587. DOI: 10.1016/ j.joen.2012.09.010.

7. Bezgin T, Yilmaz AD, Celik BN, et al. Efficacy of platelet-rich plasma as a scaffold in regenerative endodontic treatment. J Endod 2015;41(1):36-44. DOI: 10.1016/j.joen.2014.10.004.
8. Narang I, Mittal N, Mishra N. A comparative evaluation of the blood clot, platelet-rich plasma, and platelet-rich fibrin in regeneration of necrotic immature permanent teeth: a clinical study. Contemp Clin Dent 2015;6(1):63-68. DOI: 10.4103/0976-237X.149294.

9. Alagl A, Bedi S, Hassan K, et al. Use of platelet-rich plasma for regeneration in non-vital immature permanent teeth: clinical and cone-beam computed tomography evaluation. J Int Med Res 2017;45(2):583-593. DOI: 10.1177/0300060517692935.

10. Shivashankar VY, Johns DA, Maroli RK, et al. Comparison of the effect of PRP, PRF and induced bleeding in the revascularization of teeth with necrotic pulp and open apex: a triple blind randomized clinical trial. J Clin Diagn Res 2017;11(6): ZC34-ZC39. DOI: 10.7860/ JCDR/2017/22352.10056.

11. Rizk HM, AL-Deen MS, Emam AA. Regenerative endodontic treatment of bilateral necrotic immature permanent maxillary central incisors with platelet-rich plasma versus blood clot: a split mouth double-blinded randomized controlled trial. Int J Clin Pediatr Dent 2019;12(4):332-339. DOI: 10.5005/jp-journals-10005-1656.

12. Ulusoy AT, Turedi I, Cimen M, et al. Evaluation of blood clot, plateletrich plasma, platelet-rich fibrin, and platelet pellet as scaffolds in regenerative endodontic treatment: a prospective randomized trial. J Endod 2019;45(5):560-566. DOI: 10.1016/j.joen.2019.02.002.

13. Ragab RA, Lattif AE, Dokky NA. Comparative study between revitalization of necrotic immature permanent anterior teeth with and without platelet rich fibrin: a randomized controlled trial. J Clin Pediatr Dent 2019;43(2):78-85. DOI: 10.17796/1053-4625-43.2.2.

14. ElSheshtawy AS, Nazzal H, El Shahawy OI, et al. The effect of plateletrich plasma as a scaffold in regeneration/revitalization endodontics of immature permanent teeth assessed using 2-dimensional radiographs and cone beam computed tomography: a randomized controlled trial. Int Endod J 2020;53(7):905-921. 
15. Meschi N, Castro AB, Vandamme $K$, et al. The impact of autologous platelet concentrates on endodontic healing: a systematic review. Platelets 2016;27(7):613-633. DOI: 10.1080/09537104.2016.1226497.

16. Murray PE. Platelet-rich plasma and platelet-rich fibrin can induce apical closure more frequently than blood-clot revascularization for the regeneration of immature permanent teeth: a meta-analysis of clinical efficacy. Front Bioeng Biotechnol 2018;6:139. DOI: 10.3389/ fbioe.2018.00139.

17. Metlerska J, Fagogeni I, Nowicka A. Efficacy of autologous platelet concentrates in regenerative endodontic treatment: a systematic review of human studies. J Endod 2019;45(1):20-30.e1. DOI: 10.1016/ j.joen.2018.09.003.

18. Panda S, Mishra L, Arbildo-Vega HI, et al. Effectiveness of autologous platelet concentrates in management of young immature necrotic permanent teeth-a systematic review and meta-analysis. Cells 2020;9(10):2241. DOI: 10.3390/cells9102241.

19. Anitua E. Plasma rich in growth factors: preliminary results of use in preparations of future sites for implants. Int J Oral Maxillofac Implants 1999;14(4):529-535.

20. Hengameh Bakhtiar DD, Mehdi Vatanpour DD, Rayani A, et al. The plasma-rich in growth factor as a suitable matrix in regenerative endodontics: a case series. N Y State Dent J 2014;80(4):49-53.

21. Del Fabbro M, Ceresoli V, Lolato A, et al. Effect of platelet concentrate on quality of life after periradicular surgery: a randomized clinical study. J Endod 2012;38(6):733-739. DOI: 10.1016/j.joen.2012.02.022.

22. Taschieri S, Corbella S, Tsesis I, et al. Impact of the use of plasma rich in growth factors (PRGF) on the quality of life of patients treated with endodontic surgery when a perforation of sinus membrane occurred. A comparative study. Oral Maxillofac Surg 2014;18(1):43-52. DOI: 10.1007/s10006-012-0386-x.

23. Taschieri S, Rosano G, Weinstein T, et al. Treatment of through-and-through bone lesion using autologous growth factors and xenogeneic bone graft: a case report. Oral Maxillofac Surg 2012;16(1):57-64. DOI: 10.1007/s10006-010-0251-8.

24. Egusa $H$, Sonoyama W, Nishimura $M$, et al. Stem cells in dentistrypart I: stem cell sources. J Prosthodont Res 2012;56(3):151-165. DOl: 10.1016/j.jpor.2012.06.001.

25. Sonoyama W, Liu Y, Fang D, et al. Mesenchymal stem cell-mediated functional tooth regeneration in swine. PLoS One 2006;1(1):e79. DOI: 10.1371/journal.pone.0000079.

26. Huang GT-J, Sonoyama W, Liu Y, et al. The hidden treasure in apical papilla: the potential role in pulp/dentin regeneration and bioroot engineering. J Endod 2008;34(6):645-651. DOI: 10.1016/ j.joen.2008.03.001.

27. Lovelace TW, Henry MA, Hargreaves KM, et al. Evaluation of the delivery of mesenchymal stem cells into the root canal space of necrotic immature teeth after clinical regenerative endodontic procedure. J Endod 2011;37(2):133-138. DOI: 10.1016/ j.joen.2010.10.009.

28. Hargreaves KM, Diogenes A, Teixeira FB. Treatment options: biological basis of regenerative endodontic procedures. Pediatr Dent 2013;35(2):129-140.

29. Rodella LF, Favero G, Boninsegna R, et al. Growth factors, CD34 positive cells, and fibrin network analysis in concentrated growth factors fraction. Microsc Res Tech 2011;74(8):772-777. DOI: 10.1002/ jemt.20968.

30. Dohan Ehrenfest DM, Pinto NR, Pereda A, et al. The impact of the centrifuge characteristics and centrifugation protocols on the cells, growth factors, and fibrin architecture of a leukocyte-and platelet-rich fibrin (L-PRF) clot and membrane. Platelets 2018;29(2): 171-184. DOI: 10.1080/09537104.2017.1293812.

31. Mirković S, Djurdjević-Mirković T, Pugkar T. Application of concentrated growth factors in reconstruction of bone defects after removal of large jaw cysts: the two cases report. Vojnosanit Pregl 2015;72(4):368-371. DOI: 10.2298/vsp1504368m.

32. Borsani E, Bonazza V, Buffoli B, et al. Biological characterization and in vitro effects of human concentrated growth factor preparation: an innovative approach to tissue regeneration. Biol Med 2015;7(5):1. DOI: 10.4172/0974-8369.1000256.

33. Sohn DS, Moon JW, Moon YS, et al. The use of concentrated growth factors (CGF) for sinus augmentation. J Oral Implant. 2009;38(1): 25-38.

34. Doan N, Nguyen-Pham L, Liang C, et al. A review on the application of concentrated growth factors and MPhi laser to regenerate oral defects in the oral and maxillofacial region and a two cases report. Int J Oral Maxillofac Surg 2017;46(1):203-204. DOI: 10.1016/ j.ijom.2017.02.693.

35. Rodella LF, Favero G, Boninsegna R, et al. Growth factors, CD34 positive cells, and fibrin network analysis in concentrated growth factors fraction. Microsc Res Tech 2011;74(8):772-777. DOI: 10.1002/ jemt.20968.

36. Gosiewska A, Yi C-F, Blanc-Brude O, et al. Characterization of a macrophage-based system for studying the activation of latent TGF- $\beta$. Methods Cell Sci 1999;21(1):47-56. DOI: 10.1023/a:1009807802589.

37. Lakey MA, Klein MJ, Faye-Petersen OM. A comprehensive clinicopathologic analysis suggests that vascular endothelial growth factor (VEGF) is the most likely mediator of periosteal new bone formation (PNBF) associated with diverse etiologies. Clin Med Arthritis Musculoskelet Disord 2008;1:CMAMD-S442. DOI: 10.4137/ CMAMD.S442.

38. Park H-C, Kim S-G, Oh J-S, et al. Early bone formation at a femur defect using CGF and PRF grafts in adult dogs: a comparative study. Implant Dent 2016;25(3):387-393. DOI: 10.1097/ID.0000000000000423.

39. Hong S, Li L, Cai W, et al. The potential application of concentrated growth factor in regenerative endodontics. Int Endod J 2019;52(5):646-655. DOI: 10.1111/iej.13045.

40. Hong S, Chen W, Jiang B. A comparative evaluation of concentrated growth factor and platelet-rich fibrin on the proliferation, migration, and differentiation of human stem cells of the apical papilla. J Endod 2018;44(6):977-983. DOI: 10.1016/j.joen.2018.03.006.

41. Jin R, Song G, Chai J, et al. Effects of concentrated growth factor on proliferation, migration, and differentiation of human dental pulp stem cells in vitro. Journal of tissue engineering. J Tissue Eng 2018;9:2041731418817505. DOI: 10.1177/2041731418817505.

42. Jun $H$, Lei $D$, Qifang $Y$, et al. Effects of concentrated growth factors on the angiogenic properties of dental pulp cells and endothelial cells: an in vitro study. Braz Oral Res 2018;32:e48. DOI: 10.1590/18073107bor-2018.vol32.0048.

43. Malli Sureshbabu N, Selvarasu K, Nandakumar M, et al. Concentrated growth factors as an ingenious biomaterial in regeneration of bony defects after periapical surgery: a report of two cases. Case Rep Dent 2019;2019:7046203. DOI: 10.1155/2019/7046203.

44. Nivedhitha MS, Jacob B, Ranganath A. Concentrated growth factor: a novel platelet concentrate for revascularization of immature permanent teeth-a report of two cases. Case Rep Dent 2020;2020:1329145. DOI: 10.1155/2020/1329145.

45. Sureshbabu NM, Ranganath A, Jacob B. Concentrated growth factor-surgical management of large periapical lesion using a novel platelet concentrate in combination with bone graft. Ann Maxillofac Surg 2020;10(1):246-250. DOI: 10.4103/ams.ams_80_19.

46. Fang D, Long Z, Hou J. Clinical application of concentrated growth factor fibrin combined with bone repair materials in jaw defects. J Oral Maxillofac Surg 2020;78(6):882-892. DOI: 10.1016/j.joms.2020.01.037.

47. Zein N, Harmouch E, Lutz JC, et al. Polymer-based instructive scaffolds for endodontic regeneration. Materials 2019;12(15):2347. DOI: 10.3390/ma12152347.

48. Seo SJ, Kim HW, Lee JH. Electrospun nanofibers applications in dentistry. J Nanomater 2016;2016(1):1-7. DOI: 10.1155/2016/5931946.

49. Albuquerque MT, Nagata JY, Diogenes AR, et al. Clinical perspective of electrospun nanofibers as a drug delivery strategy for regenerative endodontics. Curr Oral Health Rep 2016;3(3):209-220. DOI: 10.1007/ s40496-016-0103-1.

50. Bottino MC, Kamocki K, Yassen GH, et al. Bioactive nanofibrous scaffolds for regenerative endodontics. J Dent Res 2013;92(11): 963-969. DOI: 10.1177/0022034513505770. 
51. Palasuk J, Kamocki K, Hippenmeyer L, et al. Bimix antimicrobial scaffolds for regenerative endodontics. J Endod 2014;40(11): 1879-1884. DOI: 10.1016/j.joen.2014.07.017.

52. Pankajakshan D, Albuquerque MT, Evans JD, et al. Triple antibiotic polymer nanofibers for intracanal drug delivery: effects on dual species biofilm and cell function. J Endod 2016;42(10):1490-1495. DOI: 10.1016/j.joen.2016.07.019.

53. Karczewski A, Feitosa SA, Hamer El, et al. Clindamycin-modified triple antibiotic nanofibers: a stain-free antimicrobial intracanal drug delivery system. J Endod 2018;44(1):155-162. DOI: 10.1016/ j.joen.2017.08.024.

54. Ruparel NB, Teixeira FB, Ferraz CC, et al. Direct effect of intracanal medicaments on survival of stem cells of the apical papilla. J Endod 2012;38(10):1372-1375. DOI: 10.1016/j.joen.2012.06.018.

55. Kamocki K, Nör JE, Bottino MC. Dental pulp stem cell responses to novel antibiotic-containing scaffolds for regenerative endodontics. Int Endod J 2015;48(12):1147-1156. DOI: 10.1111/iej.12414.

56. Chang B, Ahuja N, Ma C, et al. Injectable scaffolds: preparation and application in dental and craniofacial regeneration. Mater Sci Eng $\mathrm{R}$ Rep 2017;111:1-26. DOI: 10.1016/j.mser.2016.11.001.

57. Ullah F, Othman MB, Javed F, et al. Classification, processing and application of hydrogels: a review. Mater Sci Eng C Mater Biol Appl 2015;57:414-433. DOI: 10.1016/j.msec.2015.07.053.

58. Ahmed EM. Hydrogel: preparation, characterization, and applications: a review. J Adv Res 2015;6(2):105-121. DOI: 10.1016/j. jare.2013.07.006

59. Cavalcanti BN, Zeitlin BD, Nör JE. A hydrogel scaffold that maintains viability and supports differentiation of dental pulp stem cells. Dent Mater 2013;29(1):97-102. DOI: 10.1016/j.dental.2012.08.002.

60. Rosa V, Zhang Z, Grande RH, et al. Dental pulp tissue engineering in full-length human root canals. J Dent Res 2013;92(11):970-975. DOI: $10.1177 / 0022034513505772$.

61. Dissanayaka WL, Hargreaves KM, Jin L, et al. The interplay of dental pulp stem cells and endothelial cells in an injectable peptide hydrogel on angiogenesis and pulp regeneration in vivo. Tissue Eng Part $A$ 2015;21(3-4):550-563. DOI: 10.1089/ten.TEA.2014.0154.

62. Pelissari C, Paris AF, Mantesso A, et al. Apical papilla cells are capable of forming a pulplike tissue with odontoblastlike cells without the use of exogenous growth factors. J Endod 2018;44(11):1671-1676 DOI: 10.1016/j.joen.2018.08.005.

63. Jones TD, Kefi A, Sun S, et al. An optimized injectable hydrogel scaffold supports human dental pulp stem cell viability and spreading. Adv Med 2016;2016:7363579. DOI: 10.1155/2016/7363579.

64. Chrepa V, Austah O, Diogenes A. Evaluation of a commercially available hyaluronic acid hydrogel (Restylane) as injectable scaffold for dental pulp regeneration: an in vitro evaluation. J Endod 2017;43(2):257-262. DOI: 10.1016/j.joen.2016.10.026.

65. Shiehzadeh V, Aghmasheh F, Shiehzadeh F, et al. Healing of large periapical lesions following delivery of dental stem cells with an injectable scaffold: new method and three case reports. Indian J Dent Res 2014;25(2):248-253. DOI: 10.4103/0970-9290.135937.

66. Fukushima KA, Marques MM, Tedesco TK, et al. Screening of hydrogel-based scaffolds for dental pulp regenerationa systematic review. Arch Oral Biol 2019;98:182-194. DOI: 10.1016/j. archoralbio.2018.11.023.

67. Lee K, Silva EA, Mooney DJ. Growth factor delivery-based tissue engineering: general approaches and a review of recent developments. J R Soc Interface 2011;8(55):153-170. DOI: 10.1098/ rsif.2010.0223.

68. Kishen A, Hussein H. Bioactive molecule carrier systems in endodontics. Expert Opin Drug Deliv 2020;17(8):1093-1112. DOI: 10.1080/17425247.2020.1777981.

69. Shrestha S, Diogenes A, Kishen A. Temporal-controlled release of bovine serum albumin from chitosan nanoparticles: effect on the regulation of alkaline phosphatase activity in stem cells from apical papilla. J Endod 2014;40(9):1349-1354. DOI: 10.1016/ j.joen.2014.02.018.

70. Shrestha S, Diogenes A, Kishen A. Temporal-controlled dexamethasone releasing chitosan nanoparticle system enhances odontogenic differentiation of stem cells from apical papilla. J Endod 2015;41(8):1253-1258. DOI: 10.1016/j.joen.2015.03.024.

71. Bellamy C, Shrestha S, Torneck C, et al. Effects of a bioactive scaffold containing a sustained transforming growth factor- $\beta 1$-releasing nanoparticle system on the migration and differentiation of stem cells from the apical papilla. J Endod 2016;42(9):1385-1392. DOI: 10.1016/ j.joen.2016.06.017. 